\title{
BARIUM CONCENTRATIONS AS A PROXY FOR EQUATORIAL PACIFIC PRODUCTIVITY DURING THE PAST 140, 000 YEARS
}

\author{
An Undergraduate Research Scholars Thesis \\ by \\ OLUWASEYIFUNMITAN OLANIYI-SHOLANKE \\ Submitted to the Undergraduate Research Scholars program at \\ Texas A\&M University \\ in partial fulfillment of the requirements for the designation as an
}

UNDERGRADUATE RESEARCH SCHOLAR

Approved by Research Advisor:

Dr. Franco Marcantonio

May 2017

Major: Geology 


\section{TABLE OF CONTENTS}

Page

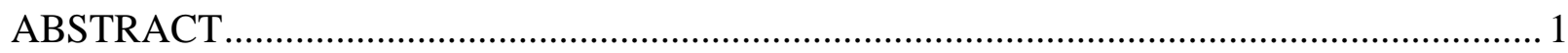

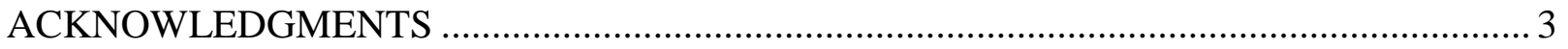

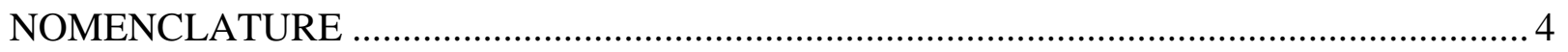

\section{CHAPTER}

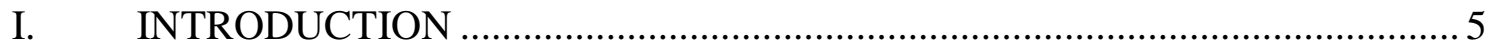

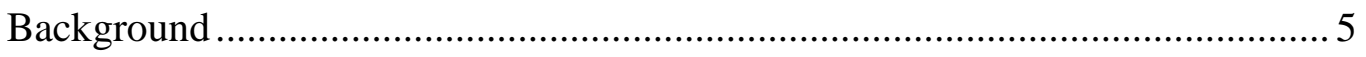

Productivity Changes and Dust Flux ................................................................ 6

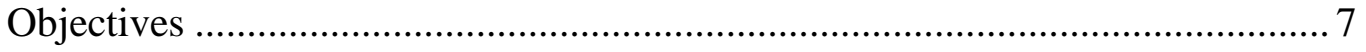

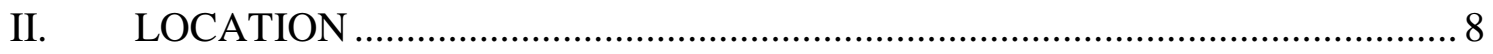

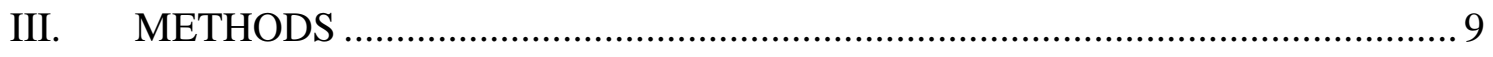

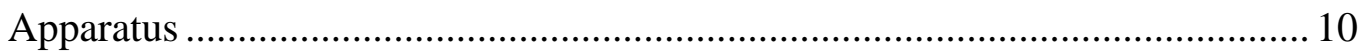

Pre-digestion Procedure ............................................................................... 10

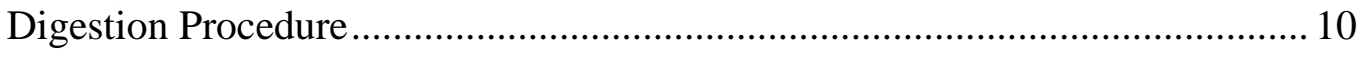

Post-digestion Procedure .................................................................................. 10

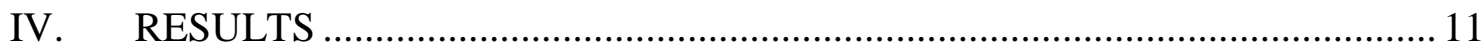

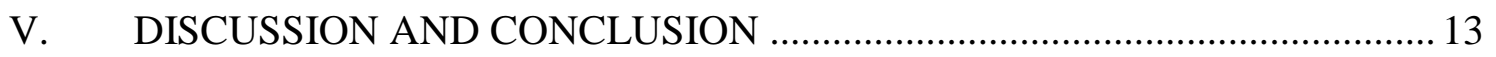

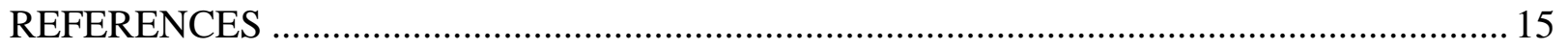

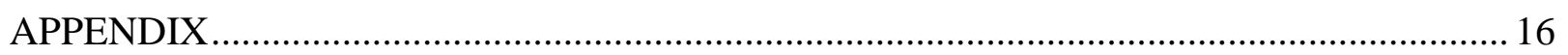




\author{
ABSTRACT \\ Barium Concentrations as a Proxy for Equatorial Pacific Productivity \\ During the Past 140,000 Years \\ Oluwaseyifunmitan Olaniyi-Sholanke \\ Department of Geology \& Geophysics \\ Texas A\&M University \\ Research Advisor: Dr. Franco Marcantonio \\ Department of Geology \& Geophysics \\ Texas A\&M University
}

The accumulation of biogenic sediments in the deep ocean may yield important information about past ocean productivity and its relationship to climate change. Sediments, sampled at approximately millennial resolution, every $4-5 \mathrm{~cm}$ on average, were obtained from a core (ML1208-17PC) retrieved from the Central Equatorial Pacific (CEP) ocean $\left(0.48^{\circ} \mathrm{N}, 156.45^{\circ} \mathrm{W}\right.$; water depth $\left.2,926 \mathrm{~m}\right)$. The main objectives of this research were to (1) use barium concentrations in marine sediments as a proxy for past ocean export production, and to (2) determine how past glacial-interglacial changes in productivity are related to climate and, specifically, variability of dust fluxes which, in turn, are a function of changing atmospheric circulation patterns.

Ba concentrations on complete digestions of bulk sediment were measured by inductively-coupled plasma mass spectrometry. Sediments ranging in age from late Holocene to 140 kyr yielded bulk barium concentrations that ranged from about 305 to $670 \mathrm{ppm}$. The authigenically-derived portion of the total barium, thought to be correlated with export production, is denoted as the biogenically-derived barium (bioBa). Using accumulation rates 
derived by Jacobel et al. (2017), we found bioBa accumulation rates that ranged from about 0.5 to $1.0 \mathrm{mg} \mathrm{cm}^{-2} \mathrm{kyr}^{-1}$. For this research, the following hypotheses were tested:

1.) BioBa fluxes (i.e., productivity) will be higher at the equatorial site, during the last glacial maximum (Marine oxygen Isotope stage 2 (MIS 2); i.e. 25 - 12 kyr), than the same fluxes during the MIS 1 (i.e., $12-0$ kyr).

2.) BioBa fluxes (i.e. productivity) will be higher during glacial MIS 4 and MIS 6 than those during interglacial MIS 3 and MIS 5.

Over the past $140 \mathrm{kyr}$, there is a positive relationship between productivity and warm interglacial periods which, in turn, are anti-correlated with dust fluxes determined by Jacobel et al. (2017). Thus, high bioBa accumulation rates correspond to less dusty warm periods, and vice versa. Productivity is apparently not a function of dust fertilization in the central equatorial Pacific, on Milankovitch glacial-interglacial timescales. 


\section{ACKNOWLEDGEMENTS}

I would like to thank my faculty advisor, Dr. Franco Marcantonio, for his guidance and continuous support through the scheme of this research project.

Also, I would like to express my sincere gratitude to Maria Reimi, Mathew Loveley, Luz Romero and Marilyn Wisler for their help and insight through the course of my research.

Finally, thanks to my family for their encouragement and love. 


\section{NOMENCLATURE}

\begin{tabular}{|c|c|}
\hline $\mathrm{Ba}$ & Barium \\
\hline $\mathrm{BaSO}_{4}$ & Barite: Barium Sulfate \\
\hline bioBa & Biogenic barium \\
\hline CEP & Central Equatorial Pacific \\
\hline $\mathrm{C}_{\text {org }}$ & Organic carbon \\
\hline $\mathrm{CO}_{2}$ & Carbon dioxide gas \\
\hline $\mathrm{HClO}_{4}$ & Perchloric acid \\
\hline $\mathrm{HF}$ & Hydrofluoric acid \\
\hline $\mathrm{HNO}_{3}$ & Nitric acid \\
\hline Kyr & Thousand years ago \\
\hline MIS & Marine oxygen Isotope Stage \\
\hline MAR & Mass Accumulation Rate \\
\hline $\mathrm{MQ}-\mathrm{H}_{2} \mathrm{O}$ & MilliQ water (Distilled water) \\
\hline NIST & National Institute of Standards and Technology \\
\hline ppm & parts per million \\
\hline $\mathrm{R} / \mathrm{V}$ & Research Vessel \\
\hline Th & Thorium (232) \\
\hline
\end{tabular}




\section{CHAPTER I}

\section{INTRODUCTION}

\section{Background}

Barium (Ba) concentrations in marine sediment can be used as a proxy for past ocean productivity and, therefore, in the reconstruction of past climates. In upwelling zones, sediments are characterized with high barite concentrations (Goldberg and Arrhenius, 1958). Barium present in ocean waters is generated through precipitation within areas of decaying biogenic material. The mineral barite $\left(\mathrm{BaSO}_{4}\right)$ is the main carrier of biogenically-precipitated $\mathrm{Ba}$ (hereafter referred to as bioBa) in sediments (Goldberg and Arrhenius, 1958; Dehairs et al., 1980; Dymond et al., 1992). Marine barite consists of approximately $50-100 \%$ of the total nondetrital, solid-phase Ba in the water column (Goldberg and Arrhenius, 1958).

Ba concentrations are higher in nutrient rich waters, implying that the formation of barite is controlled by biota (Dehairs, 1980). In addition, the association of Ba with biogenic material is inferred from Ba-rich sediments that underlie very productive surface waters (Dehairs, 1980). The amount of barite precipitation is highly related to the dissolution of $\mathrm{Ba}$ in seawater and the decomposition of organic matter $\left(\mathrm{C}_{\mathrm{org}}\right)$. Because of its association with organic carbon, barite present in marine sediments is commonly used to understand past paleoproductivity levels (Paytan and Griffith, 2007). In addition, barite and bioBa sediment concentrations have been

used by geologists to study temporal paleoproductivity changes in the ocean (Dymond et al., 1992), and the relationship these changes have with global climate variability.

The potential of bioBa as a proxy for productivity is significant because barite is wellpreserved in marine sediments. The ratio of $\mathrm{C}_{\mathrm{org}}$ to bioBa decreases with depth in the water 
column; this is because with increased bioBa flux, there is a decrease in $\mathrm{C}_{\text {org }}$ flux. This relationship highlights the viability of barium as a paleoproductivity, and it shows the capability of bioBa to withstand geological processes such as diagenesis (unlike $\mathrm{C}_{\text {org }}$ ), which may recycle material back to the water column (Rushdi et al.,2000).

\section{Productivity Changes and Dust Flux}

The growth of phytoplankton in the oceans is intimately associated with the carbon cycle and, therefore, the $\mathrm{CO}_{2}$ content of the atmosphere and climate variability. When phytoplankton growth rates are high, there is more carbon exported to the deep sea so that $\mathrm{CO}_{2}$ levels in the atmosphere remain low.

The variability of dust flux is a function of changing atmospheric circulation patterns. High dust fluxes have been associated with glacial time intervals (McGee et al. 2010). Indeed, the cause of the increased dust fluxes may be related to increases in gustiness of the dust sources area, which may characterize glacial periods even at a millennial resolution (McGee et al., 2010). Changes in dust fluxes may play an important role in changing productivity of the oceans through time. When dust dissolves in seawater, it releases iron which is an important micronutrient for phytoplankton growth. One might expect, therefore, that when dust fluxes are high, there may be increased efficiency of the export of $\mathrm{CO}_{2}$ to the ocean bottom (because of increased productivity), where it is isolated from the surface ocean/atmospheric system.

Costa et al. (2016) assert that the greater dust flux of the last glacial period was not large enough to generate significant iron fertilization and increased productivity. A similar conclusion was reached by Winckler et al. (2016) who additionally suggested that iron, rather than being provided by increased dust fluxes, may be provided to the surface ocean as a result of diffusive and advective upwelling along the equator. Thus, dust fertilization of the ocean may not 
contribute to the changing patterns of productivity in the Central Equatorial Pacific (CEP). These hypotheses will be further tested here.

\section{Objectives}

The main objectives of this research were to (1) use concentrations of barium in marine sediments as a proxy for past ocean export production, and to (2) determine how past glacialinterglacial changes in productivity are related to climate and, specifically, variability of dust fluxes.

For this research, the following hypotheses were tested:

1.) BioBa fluxes (i.e., productivity) will be higher at the equatorial site, during the last glacial maximum (marine oxygen isotope stage 2 (MIS 2); i.e. 25 - $12 \mathrm{kyr}$ ), than the same fluxes during the MIS 1 (i.e., $12-0$ kyr).

2.) BioBa fluxes (i.e. productivity) will be higher during glacial MIS 4 and MIS 6 than those during interglacial MIS 3 and MIS 5. 


\section{CHAPTER II}

\section{LOCATION}

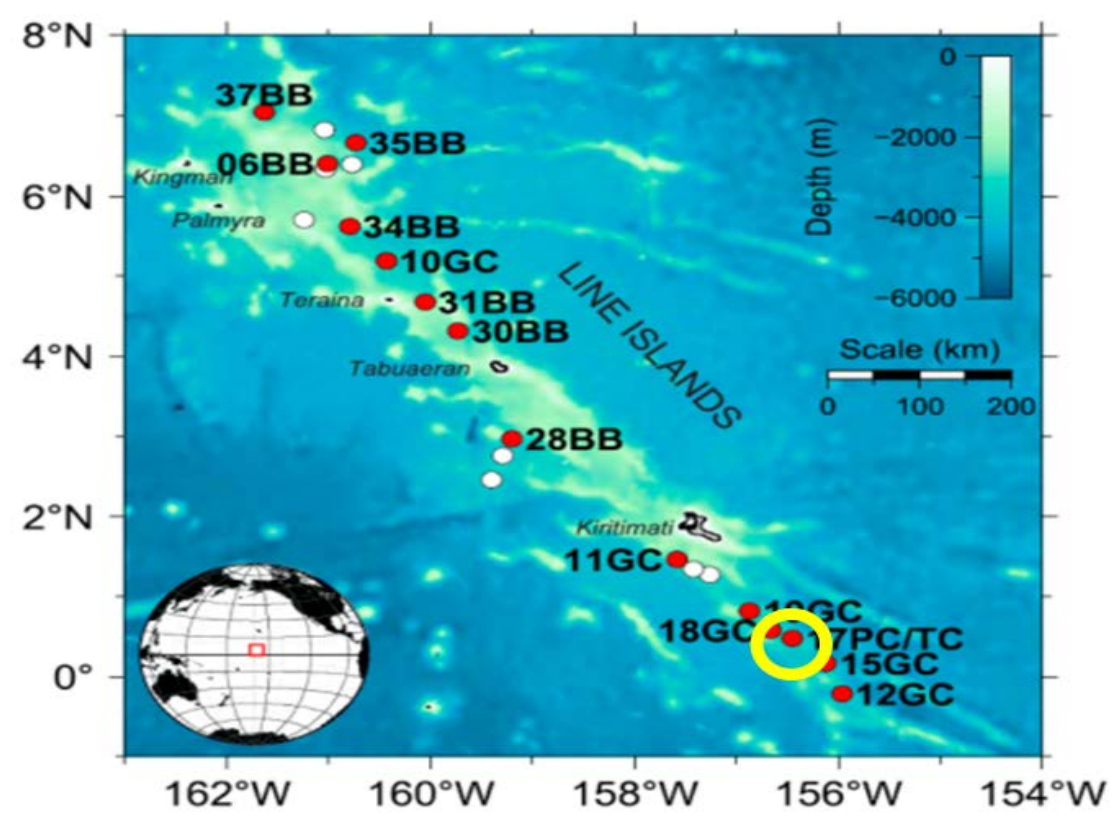

Figure 1: Location of the core: 17PC (yellow circle). Modified from Lynch-Stieglitz et al. (2015).

Sediments, sampled at approximately millennial resolution, were obtained from a core (ML1208-17PC; see location in Figure 1) retrieved from the Central Equatorial Pacific (CEP) $\left(0.48^{\circ} \mathrm{N}, 156.45^{\circ} \mathrm{W}\right.$; water depth $\left.2,926 \mathrm{~m}\right)$. The study area is in the Line Islands, which form part of series of atolls, seamounts and volcanic ridges. The core studied here (17PC), in addition to several other cores (outlined in Figure 1), were collected by Dr. Jean Lynch-Stieglitz at the Georgia Institute of Technology as part of a research cruise aboard the R/V Marcus Langseth. 


\section{CHAPTER III}

\section{METHODS}

Homogenized sediment samples ( 50 mg) were completely digested using a cocktail of $\mathrm{HNO}_{3}, \mathrm{HF}$, and $\mathrm{HClO}_{4}$. Additionally, blanks and NIST standard 2702, run under the same conditions as the sediment samples, were measured as part of this study. Biogenic barium (bioBa) concentrations, defined as the fraction of total Ba not associated with terrigenous material, were estimated by subtracting the concentration of detrital barium from the total measured barium. The detrital fraction of $\mathrm{Ba}$ was estimated assuming that the $\mathrm{Ba} / \mathrm{Th}$ ratio of the sediments is same as the $\mathrm{Ba} / \mathrm{Th}$ ratio of average upper crust (51.4, i.e., $550 \mathrm{ppm}$ for Ba and 10.7 ppm for Th, Taylor and McLennan, 1985). Therefore, bioBa concentration can be derived by using equation (1):

$$
[\mathrm{bioBa}]=[\mathrm{Ba} \text { total measured }][\mathrm{Ba} / \mathrm{Th}]_{\text {terrigenous }} *\left[{ }^{232} \mathrm{Th}\right]
$$

where the ${ }^{232}$ Th concentration is given for the samples at the same depths in Jacobel et al. (2017). In addition, in order to understand the changes associated with the biogenic barium profile, the bioBa flux was calculated using Eq. (2):

bioBa flux $=($ bioBa $) *{ }^{230}$ Th-derived sediment Mass Accumulation Rate

where the ${ }^{230}$ Th-derived sediment Mass Accumulation Rate is given for the same sample intervals in Jacobel et al. (2017). 


\section{Apparatus}

Equipment used for the pre-digestion, digestion and post-digestion procedures include, an analytical balance, spatula, $50 \mathrm{~mL}$ centrifuge tubes, fume hood, $15 \mathrm{~mL}$ Savillex beakers and pipette (1000 micro liters).

Acids used were perchloric acid $\left(\mathrm{HClO}_{4}\right)$, nitric acid $\left(\mathrm{HNO}_{3}\right)$ and hydrofluoric acid $(\mathrm{HF})$.

$\mathrm{HF}$ and $\mathrm{HClO}_{4}$ broke down the silicates in the samples and $\mathrm{HNO}_{3}$, an oxidizing agent, promoted further dissolution.

\section{Pre-digestion Procedure}

$50 \mathrm{mg}$ of the core samples were measured and added to a $15 \mathrm{~mL}$ Savillex beaker. The walls of the beakers were rinsed with approximately $0.5 \mathrm{~mL} \mathrm{MQ}-\mathrm{H}_{2} \mathrm{O}$ to dissolve sample. The hot plate was heated to $170^{\circ} \mathrm{C}$ and the Savillex beakers containing the samples were placed on the hot plate.

\section{Digestion Procedure}

$3 \mathrm{~mL}$ of $\mathrm{HClO}_{4}$ and $1 \mathrm{~mL}$ of $\mathrm{HNO}_{3}$ were added to the samples consecutively and was left to sit on the hot plate for approximately 40 minutes. Then, $2 \mathrm{~mL}$ of HF was added to the samples and left to sit for approximately 20 minutes. The aforementioned step was repeated twice. Lastly, $1 \mathrm{~mL}$ of $\mathrm{HNO}_{3}$ was added to the samples.

\section{Post-Digestion Procedure}

The digested samples in the Savillex beakers were transferred to pre-weighed $50 \mathrm{~mL}$ centrifuge tubes and filled with MQ- $\mathrm{H}_{2} \mathrm{O}$ to the $25 \mathrm{~mL}$ mark on the centrifuge tubes.

Concentrations of $\mathrm{Ba}$ in the digested samples were measured by inductively-coupled plasma mass spectrometry. Blank corrections were negligible and NIST standard 2702 was accurate to within about 5\%. 


\section{CHAPTER IV}

\section{RESULTS}

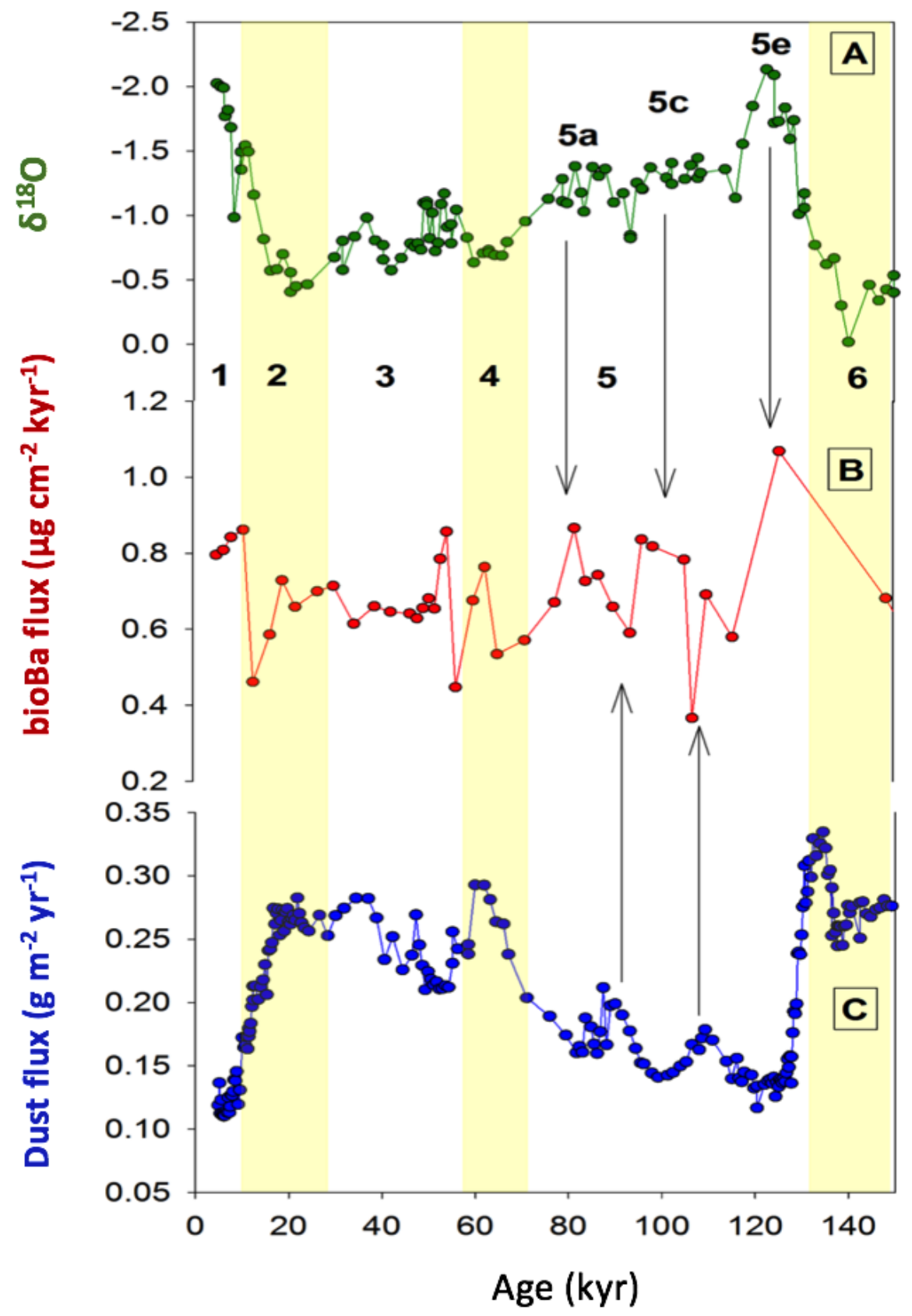

Figure 2. Oxygen isotope curve (A) for core 17PC from Lynch-Stieglitz et al. (2015) and 230Thderived dust flux (C) from Jacobel et al. (2017). Our BioBa flux (B) in middle panel. Bold numbers represent marine oxygen isotope stages (MIS 1, 3, 5 represent warm interglacial periods and MIS 2, 4, 6 represent cool glacial periods). 
The oxygen isotope curve in Figure 2 (oxygen isotope data from Lynch-Stieglitz et al., 2015) was used to determine the chronology of sediments retrieved from core ML1208-17PC. By identifying MIS boundaries, we can understand the temporal paleoproductivity changes in the ocean on a glacial-interglacial timescale.

Sediments ranging in age from late Holocene to $140 \mathrm{kyr}$ yielded bulk barium concentrations that ranged from about 305 to $670 \mathrm{ppm}$. The authigenically-derived portion of the total barium, thought to be correlated with export production, is denoted as bioBa. The bioBa was estimated by subtracting the lithogenic Ba from the total Ba. Lithogenic Ba contents were calculated using thorium concentrations in the same samples (Jacobel et al., 2017). Our results show that the sediment samples yielded bioBa concentrations ranging from approximately 298 to $662 \mathrm{ppm}$, and bioBa flux values from approximately 0.447 to $1.068 \mu \mathrm{g} \mathrm{cm}^{-2} \mathrm{kyr}^{-1}$. The bioBa makes up greater than $97 \%$ of the total Ba. Using accumulation rates derived by Jacobel et al. (2017), we found bioBa accumulation rates that range from about 0.5 to $1.0 \mathrm{mg} \mathrm{cm}^{-2} \mathrm{kyr}^{-1}$. 


\section{CHAPTER V}

\section{DISCUSSION AND CONCLUSION}

In the water column, the covariation of barium abundance and its associated fluxes demonstrate the influence and effects of marine biological cycles. In combination with the flux of organic carbon, bioBa fluxes present in sediment records can be used to infer and characterize paleoproductivity. As shown in Figure 2, there is a positive relationship between productivity (bioBa flux) and warm interglacial periods. In general, productivity is lower during colder periods (MIS 2, 4, and 6) than during warmer periods (MIS 1, 3, 5). Even within interglacial MIS 5, there is a strong precessional relationship with bioBa fluxes (i.e., bioBa flux peaks and troughs correlate with 5a-e).

Dust deposition in the central Equatorial Pacific during the last glacial period (MIS 2) was approximately 2-3 times greater than it was during the Holocene (Jacobel et al., 2017). High glacial dust flux has been recognized to correlate with changes in wind strength, or changes in source aridity (McGee et al. 2010). We find no evidence for high bioBa accumulation rates during the last three glacial time periods (MIS 2, 4, and 6). Instead, we fine the highest bioBa accumulation rates during the warm interglacial periods (MIS 1, 3, and 5), times during which, there was significantly less dust being delivered to the Central Equatorial Pacific Ocean. This is the same pattern identified by Costa et al. (2016) in MIS 1 and MIS 2, although we extend the timing of this finding from $25 \mathrm{kyr}$ to $140 \mathrm{kyr}$. Costa et al. (2016) believed that the changes in bioBa flux were not related to changes in dust flux because the increase in, dust flux during the last glacial period was not large enough to generate significant iron fertilization to the central Equatorial Pacific. Furthermore, the lack of a positive relationship between our bioBa flux and 
dust flux (Figure 2), suggests that nutrients like iron may be provided to the euphotic zone as a result of diffusive and advective upwelling of waters from the Equatorial Undercurrent, as asserted by Winckler et al. (2016). Thus, dust fertilization of the ocean is apparently not contributing to the measure of productivity in the Central Equatorial Pacific (CEP), at least on Milankovitch glacial-interglacial timescales. 


\section{REFERENCES}

Costa, K. M., McManus, J.F., Anderson, R.F., Winckler, G., Fleisher, M.Q., Ren, H.; Sigman, D.M., Marcantonio, F., Ravelo, A.C., 2016. No iron fertilization in the equatorial Pacific Ocean during the last ice age. Nature, 529(7587): 519-522.

Dehairs, F., Chesselet, R., Jedwab, J., 1980. Discrete Suspended Particles of Barite and the Barium Cycle in the Open Ocean. Earth and Planetary Science Letters, 49(2): 528-550.

Dymond, J., Suess, E., Lyle, M., 1992. Barium in Deep-Sea Sediment: A Geochemical Proxy for Paleoproductivity. Paleoceanography, 7(2): 163-181.

Goldberg, E. D., Arrhenius G.O.S., 1958. Chemistry of Pacific pelagic sediments. Geochimica et cosmochimica acta, 13(2).

Jacobel, A., McManus, J., Anderson, R., \& Winckler, G., 2017. Climate-related response of dust flux to the central equatorial Pacific over the past $150 \mathrm{kyr}$, Earth and Planetary Science Letters, 45(7): 160-172.

Lynch-Stieglitz, J., P. J. Polissar, A. W. Jacobel, S. A. Hovan, R. A. Pockalny, M. Lyle, R. W. Murray, A. C. Ravelo, S. C. Bova, A. G. Dunlea, et al., 2015. Glacial-interglacial changes in central tropical Pacific surface seawater property gradients. Paleoceanography, 30(5): 423-438.

McGee, D., Broecker, W. S., \& Winckler, G., 2010. Gustiness: The driver of glacial dustiness? Quaternary Science Reviews, 2(9): 2340-2350.

Paytan, A., Griffith, E.M., 2007. Marine barite: Recorder of variations in ocean export productivity. Deep-Sea Research Part Ii-Topical Studies in Oceanography, 54(5-7): 687-705.

Rushdi, A. I., McManus, J., \& Collier, R. W., 2000. Marine barite and celestite saturation in seawater. Marine Chemistry, 6(9): 19-31 
Taylor, S. R., \& McLennan, S. M.,1985. The continental crust : its composition and evolution : an examination of the geochemical record preserved in sedimentary rocks. Stuart Ross Taylor, Scott M. McLennan. Oxford ; Boston : Blackwell Scientific ; Palo Alto, Calif. : Fistributors, USA and Canada, Blackwell Scientific, 1985. 


\section{APPENDIX}

TABLE 1: SAMPLE DATA \& RESULTS

\begin{tabular}{|c|c|c|c|c|c|}
\hline Depth (cm) & Age (kyr) & Вa (ppm) & bioBa (ppm) & MAR Jacobel & $\begin{array}{c}\text { bioBa flux } \\
\left(\mu \mathrm{g} \mathrm{cm}^{-2} \mathrm{kyr}^{-1}\right)\end{array}$ \\
\hline 0 & 4.9651 & 545.8983 & 541.4476731 & 1.469131455 & 0.795457808 \\
\hline 8 & 6.51 & 558.4376 & 554.2649146 & 1.458307174 & 0.808288501 \\
\hline 16 & 8.1293 & 532.2788 & 527.8073021 & 1.595629302 & 0.842184797 \\
\hline 24 & 10.74977 & 570.7701 & 564.7775768 & 1.525941498 & 0.861817542 \\
\hline 32 & 12.82096 & 492.0993 & 479.8968555 & 0.960612897 & 0.460995109 \\
\hline 40 & 16.41955 & 317.45 & 310.2478755 & 1.88841902 & 0.585877989 \\
\hline 48 & 19.04953 & 447.6198 & 439.1210159 & 1.659209553 & 0.728593785 \\
\hline 56 & 21.8485 & 403.4855 & 394.1929314 & 1.67222302 & 0.659178494 \\
\hline 64 & 26.59273 & 404.7309 & 396.3540247 & 1.765464845 & 0.699749097 \\
\hline
\end{tabular}


Table 1 continued

\begin{tabular}{|c|c|c|c|c|c|}
\hline Depth (cm) & Age (kyr) & Ba (ppm) & bioBa (ppm) & MAR Jacobel & $\begin{array}{c}\text { bioBa flux } \\
\left(\mu \mathrm{g} \mathrm{cm}^{-2} \mathrm{kyr}^{-1}\right)\end{array}$ \\
\hline 72 & 30.07754 & 396.45 & 388.413135 & 1.83779656 & 0.713824324 \\
\hline & & & & & \\
\hline 80 & 34.43505 & 305.3774 & 297.8506768 & 2.063176987 & 0.614518662 \\
\hline 88 & 38.84054 & 329.2071 & 322.0476269 & 2.049993302 & 0.660195478 \\
\hline 96 & 42.29598 & 376.3658 & 368.4648825 & 1.753202174 & 0.645993433 \\
\hline 104 & 46.4258 & 310.528 & 304.3312496 & 2.107437449 & 0.641359072 \\
\hline 112 & 47.99531 & 311.2037 & 304.6616755 & 2.063078986 & 0.6285411 \\
\hline 120 & 49.25659 & 329.7279 & 324.0202783 & 2.023762901 & 0.655740218 \\
\hline 128 & 50.48394 & 343.6308 & 337.6731853 & 2.016379422 & 0.680877262 \\
\hline 136 & 51.70295 & 353.7469 & 347.4303331 & 1.883174509 & 0.654271947 \\
\hline 144 & 52.95329 & 391.9591 & 386.2504583 & 2.032853735 & 0.785190687 \\
\hline 152 & 54.32191 & 415.81 & 410.2285512 & 2.089357023 & 0.857113904 \\
\hline
\end{tabular}


Table 1 continued

\begin{tabular}{|c|c|c|c|c|c|}
\hline Depth (cm) & Age (kyr) & Ba (ppm) & bioBa (ppm) & MAR Jacobel & $\begin{array}{c}\text { bioBa flux } \\
\left(\mu \mathrm{g} \mathrm{cm}^{-2} \mathrm{kyr}^{-1}\right)\end{array}$ \\
\hline 160 & 56.25754 & 380.878 & 369.8463264 & 1.208381594 & 0.446915494 \\
\hline & & & & & \\
\hline 168 & 59.97301 & 359.7726 & 351.4027907 & 1.924014725 & 0.676104144 \\
\hline 176 & 62.5 & 444.1301 & 434.9644553 & 1.75609697 & 0.763839762 \\
\hline 184 & 65.2 & 380.5405 & 370.5367638 & 1.440945104 & 0.533923136 \\
\hline 192 & 71.06599 & 355.3843 & 348.5515018 & 1.63866061 & 0.571157616 \\
\hline 200 & 77.5 & 434.238 & 428.1245894 & 1.566868674 & 0.670815008 \\
\hline 208 & 81.71422 & 507.1446 & 502.0336968 & 1.725256747 & 0.866137022 \\
\hline 216 & 84.1 & 487.2153 & 480.3879628 & 1.51201783 & 0.726355165 \\
\hline 224 & 86.78971 & 441.7794 & 436.0680686 & 1.703446326 & 0.742818549 \\
\hline 232 & 89.98339 & 420.6635 & 413.7933773 & 1.592578974 & 0.658998632 \\
\hline 240 & 93.6 & 394.3997 & 387.9849499 & 1.521311249 & 0.590245869 \\
\hline
\end{tabular}


Table 1 continued

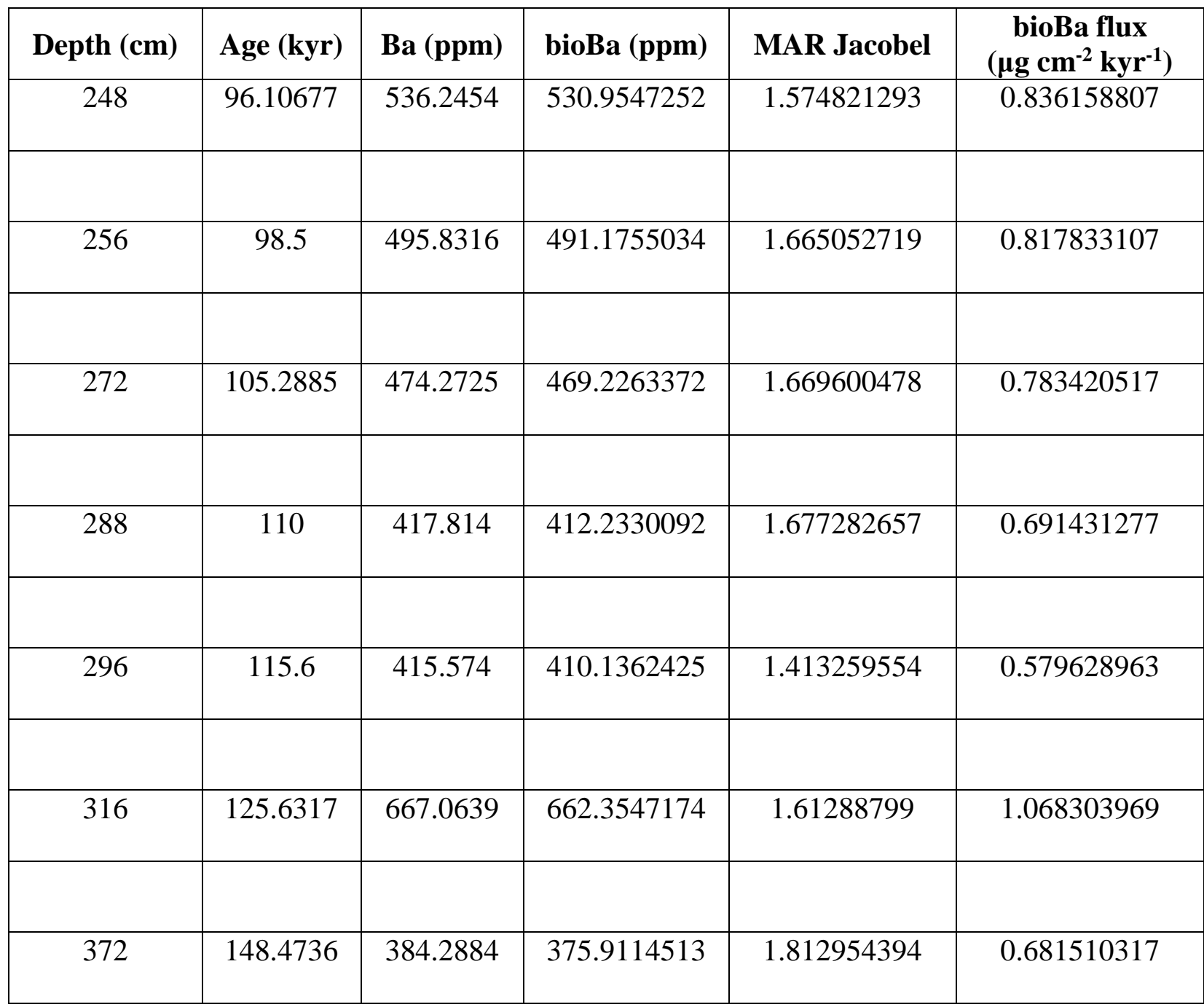

